\title{
Performance of Counter Flow Heat Recovery Ventilation Systems in Dwellings Considering the Influence of Uncertainties
}

\author{
Zhiming Yang, JJM Cauberg and MJ Tenpierik \\ Climate Design, Building Technology, Delft University of Technology. Julianalaan 134, 2628 BL, \\ Delft, The Netherlands
}

\begin{abstract}
Both critical and optimistic claims have been made regarding the performance of heat recovery ventilation systems (HRVS) in dwellings. Such arguments are raised partly because two key aspects are not fully clarified, i.e. the performance criteria and the influence of uncertainties. In the current paper, an assessment method for HRVS considering the influence of uncertainties is described. This includes adequate assessment criteria, the method of identifying the uncertainties, and the method of addressing the influence of such uncertainties. The performance criteria consider the airflow performance, supply air quality and energy performance. Uncertainties in four aspects, including ventilation component, building properties, outdoor environment and occupant behaviour, are defined and related to five uncertainty sources ranging from the design phase to usage phase, i.e. design alternative, specification uncertainty, production deviation, modelling uncertainty and stochastic process. The estimation methods are given for each type of uncertainty based on the sources. Then, the method of carrying out the uncertainty analysis is introduced. This includes the calculation steps under a given commissioning status of the ventilation system, the uncertainty quantification techniques and the calculation steps. Afterwards, the method is applied to a case study of a counter flow heat recovery ventilation system in a reference Dutch house with the aid of simulations. Generally speaking, the method proposed in this article can provide an adequate framework for analysing or assessing the performance of HRVS in houses. As such it may contribute to a better understanding and a better design of this type of ventilation system.
\end{abstract}

Key words: assessment criteria, heat recovery ventilation, uncertainties, MVHR.

\section{Introduction}

Since the energy crisis in the 1970 s people became aware of the importance of energy saving in various fields including the housing stock. In particular the energy loss due to air exchange was found to have a crucial share in the total energy consumption of buildings. Therefore, various types of ventilation systems with different types of heat recovery units or heat exchangers have been developed and have been widely employed in the housing stock especially in countries with typical moderate and cold climate patterns.

Though being considered as a promising ventilation system for reducing energy use, the overall performance of such heat recovery ventilation systems (HRVS) is still, to some extent, arguable. Such arguments are mostly related to the energy performance. Optimism can be easily found in the manufacturers' brochures which normally give the best set of test results of the heat recovery efficiency. Positive opinions can also be found in literature. For example, Schild and Brunsell (2003) studied the actual performance of HRVS in Finland and claimed that the HRVS are a mature technology and could pay the investment back in about 4-6 years. Recently, more optimism indicating that high primary energy savings could be achieved by HRVS in heated apartments was shown (Dodoo et al, 2011). On the other hand, critical voices about the benefits of such HRVS have also been raised. Roulet et al (2001) discussed the calculation method of real energy saving benefits for a HRVS and claimed that measurement data showed that, in some cases, the heat recovery efficiency of the heat exchanger was only about $70 \%$ while the net energy saved (heat recovered minus the energy consumed for running the system) could even be negative.

Two aspects may have contributed to such differences among the performances of the HRVS: the definition and calculation of performance 
criteria and the uncertainties in testing or calculation boundary conditions/assumptions.

Although the term "heat recovery efficiency" is widely used for expressing the performance of the HRVS, heat recovery efficiency may have various definitions. Some researchers focus on the heat recovery efficiency purely of the heat recovery units (by measuring the temperature differences of the air flow at the inlet and outlet ducts) while others consider the effects of building infiltration and duct leakage, and the electricity used by the fans to operate the mechanical heat recovery ventilation system. A good heat recovery efficiency of the heat recovery unit, however, neither necessarily means a good efficiency considering the infiltration and system leakage nor net energy benefit.

The second factor influencing the conclusions on the performance of heat recovery ventilation systems are the uncertainties in measurements or in calculation boundary conditions. The results expressed by different performance criteria are highly dependent on the values of the input parameters, which may have large variations in their values in practice. Such variations partly contribute to the uncertainties.

Uncertainty quantification studies have been applied to some fields related to building performance evaluation and simulation. This includes the work of de Wit (2002) and Macdonald (2002). More uncertainty studies related to ventilation can be found in Wouters et al (2004), Hyun et al (2008) and Costola et al (2010). However, uncertainty quantification analysis has not been widely used in the performance calculation of the HRVS and no overall assessment framework that considers these uncertainties has yet been established. To understand the overall performance of heat recovery ventilation systems in practice, uncertainty quantification analysis can provide useful information.

Above all, to better understand the performance that a HRVS can provide, the suitable criteria and the influence of uncertainties should be addressed. Thus, in this paper we introduce a method for assessing the performance of the HRVS in houses which takes into account the influence of uncertainties, including the performance criteria, a method for the identification of various uncertainties and methods for dealing with the effect of such uncertainties. Subsequently, this simulation method is applied to a case study to analyse the performance of a counter flow heat recovery ventilation system.

\section{Performance Criteria}

In assessing the performance of the HRVS two main aspects are considered, i.e. the supply air quality and the energy performance. The relevant indicators are introduced and defined below.

\section{Exhaust Airflow Rate}

Exhaust airflow rate at the exhaust air grilles, expressed in $\mathrm{m}^{3} / \mathrm{h}$.

\section{Supply Airflow Rate}

In the case of supply air, duct leakage and internal leakage may affect the supply air quality by causing unwanted internal recirculation. Thus the mechanical supply airflow rates are calculated by considering the contribution of fresh air (outside air) and the recirculation air (both designed and unwanted). Thus the hourly supply airflow rate for each room or zone can be calculated by:

$q_{\text {sup }}=\sum_{n}\left(\alpha_{n} q_{n}\right)$

where:

$q_{\text {sup }}=$ the adjusted airflow supply rate considering the quality of supply air, in $\mathrm{m}^{3} / \mathrm{h}$

$q_{n}=$ the airflow rates for various flow segments entering into the room, for example $q_{\text {sup }}$ and $q_{\text {rec,u }}$ representing the supply air flows of total mechanical supply, and unwanted recirculation in the supply airflow (internal leakage) respectively,

$\alpha_{n}=$ the contribution factor of each airflow segment mentioned above which normally can be set to 1 (for example, the outdoor fresh air), 0 (for infiltration) and negative value (if the airflow is considered to be harmful).

\section{Unwanted Airflow Direction}

This is the unexpected airflow from polluted rooms to habitable space.

\section{Net Energy Saved by Heat Recovery Unit (NES)}

NES is generally defined as the energy recovered by the heat recovery unit minus the energy consumed by the fans driving the airflow. The concept of net energy saved by heat recovery unit has been used by many researchers before. It aims to reflect the true benefits of a heat recovery ventilation system. In the current paper, NES can be calculated from Equation (2) below:

$N E S=E R-E C$ 


$$
\begin{aligned}
& E R=\rho C \sum_{j}\left(T_{\text {outlet }, s u, j}-T_{\text {inlet }, s u, j}\right) q_{\text {su }, j} \\
& E C=\sum_{i} \sum_{j} \frac{V_{i . j} \cdot \Delta P_{i . j}}{\eta_{\text {fan }, i}}
\end{aligned}
$$

where:

$E R \quad=$ energy recovered by the heat recovery unit, in $\mathrm{kJ}$;

$E C=$ electricity consumed by the fans, in $\mathrm{kJ}$;

$\rho \quad=$ air density at the average temperature of the heating season, in $\mathrm{kg} / \mathrm{m}^{3}$;

$C \quad=$ specific heat of air, in $\mathrm{kJ} / \mathrm{kg} \cdot \mathrm{K}$;

$q_{s u, j}=$ amount of supply air leaving the heat recovery unit in the $\left(\mathrm{j}^{\text {th }}\right)$ hour, in $\mathrm{m}^{3}$;

$T_{\text {outlet,su }, j}=$ air temperature at the outlet on the supply side of the heat recovery unit in the $\left(j^{\text {th }}\right)$ hour, in $\mathrm{K}$;

$T_{\text {inlet,su }, j}=$ air temperature at the inlet on the supply side of the heat recovery unit in the $\left(\mathrm{j}^{\text {th }}\right)$ hour, in $\mathrm{K}$;

$V_{i, j} \quad=$ volume of the airflow across the fan (i) in the $\left(\mathrm{j}^{\text {th }}\right)$ hour, in $\mathrm{m}$;

$\Delta P_{i, j}=$ pressure drop crossing fan (i) in the $\left(\mathrm{j}^{\text {th }}\right)$ hour , in $\mathrm{Pa}$;

$\eta_{f a n, i}=$ fan efficiency of fan (i), in \%.

\section{Global Heat Recovery Efficiency}

Normally, research into the efficiency of heat recovery considers the contribution of the heat exchanger. This focus may stimulate improvements of the heat recovery efficiency of the heat exchangers but may ignore other important factors that influence the overall energy consumption related to ventilation, for example air infiltration. If the system boundary is the whole building, the total energy loss due to air change of the system or the building can be calculated.Then we can obtain the global heat recovery efficiency from:

$$
\eta_{G}=\frac{E R}{Q_{l o s s}}
$$

and

$$
Q_{l o s s}=\rho C \sum_{i} \sum_{j}\left(q_{e x, i, j} \mathrm{~T}_{e x, i, j}-q_{s u, i, j} \mathrm{~T}_{s u, i, j}\right)+E R
$$

where:

$Q_{\text {loss }}=$ total energy loss due to air change, in $\mathrm{kJ}$;

$q_{e x, i, j}=$ amount of air exhausted from a certain segment (i) of air flows in the $\left(\mathrm{j}^{\text {th }}\right)$ hour, in $\mathrm{m}^{3}$;

$q_{s u, i, j}=$ amount of air supplied to a certain segment (i) of airflows in the $\left(\mathrm{j}^{\text {th }}\right)$ hour, in $\mathrm{m}^{3}$;
$T_{e x, i, j}=$ temperature of the air exhausted from a certain segment (i) of airflow in the $\left(j^{\text {th }}\right)$ hour, in $\mathrm{K}$.

$T_{s u, i, j}=$ temperature of the air supplied to a certain segment (i) of airflow in the $\left(\mathrm{j}^{\text {th }}\right)$ hour, in $\mathrm{K}$.

\section{Uncertainty Quantification}

\subsection{Uncertainty Resources}

Uncertainty is defined as that part of the value of a parameter which cannot be fully specified when carrying out an assessment or analysing the process of a performance. In practice, there are four aspects which can influence the actual performance of a balanced ventilation system:

- Ventilation components

- Building properties

- Outdoor environment

- Occupant behaviour

For each aspect, there are parameters which include uncertainties caused by various sources. For identifying the uncertainties in such aspects, five uncertainty sources are defined. For an uncertainty analysis, information from each uncertainty may be required, including the variation range and probability distribution. The description of these five uncertainty sources and proposed estimation methods for each of them are outlined below.

- Design alternative

- Specification uncertainty

- Production deviation

- Modelling uncertainty

- Stochastic process.

\section{Design Alternative}

This is the design choice which the designer has without conflicting with the design rules. For example, only the minimum requirements on the designed airflows are defined, meaning the designer could use values higher than the minimum values. If the designer has, as yet, no preferred design choice and wants to know the influence of different design choices, the design alternative could be an uncertainty source. This type of uncertainty can also be considered as a lack of specification in the design rules, but is different from specification uncertainty. The variation range should be estimated or defined 
based on the possible alternatives resulting from the design rules. For example, if a medium air tightness level is specified, the designer may have alternatives from a high air tightness level to a medium air tightness level.

\section{Specification Uncertainty}

This means that not all relevant parameters which are needed as inputs for an assessment process or calculation model are specified in the design or in the design rules. For example, in the selection of a fan, normally only the working point is considered in practice. Although the whole fan curve is not used as selection criterion, it was used in the simulations because it influences the system performance. In practice, for a given working point, there might be several types of fans with different fan curves that can be selected. This uncertainty source is related to the lack of specification in design rules. To estimate this specification uncertainty, it is first important to know which parameters are not specified and then to ascertain the variation ranges of the values of such parameters. The most straightforward way is to use measurement data of such unspecified parameters.

\section{Production (Construction) Deviation}

This is the difference between the practical properties of the products and the nominal/ theoretical properties of the products caused by the realization process. The reasons for this deviation can be summarized as two aspects: nominally identical products that are produced or constructed by different machines or workers, and the random error that may produce different results for the same process. In practice, it is difficult to completely separate these two aspects. Anyway, such uncertainties could be reflected by measurement data. Estimations are therefore best made directly through measurement. For example, for a certain type of construction, such as a window, the air leakage value could vary within a certain range. If measurement data are missing, estimations may be made based on assumptions and on the requirements in relevant standards.

\section{Modelling Uncertainty}

Modelling uncertainty involves the employment of various models to represent reality. Models are developed usually with simplifications and approximations. Arbitrarily speaking, no one model can $100 \%$ represent reality. During the assessment of a ventilation system, many inputs that are not measurable are derived from models. In the thesis written by deWit (2002) the methods for estimating modelling uncertainty were discussed. For an approximation, the scatter between different models could be used. If a stricter estimation is required, costly methods such as expert judgment, experiments and measurements may be needed.

\section{Stochastic Process}

This is related to the factors which actually require prediction, including e.g. future climate, occupancy and occupant behaviour. Such stochastic process factors are normally assumed to be certain default values or profiles in the design. Therefore, uncertainties are introduced. Different treatments of climate and occupant behaviour are used. For climate, we recommend using different typical patterns of annual weather data to represent the climate variations; for example, a typical average weather year, a typical hot year and a typical cold year. Except for the indoor heating temperature, the other defined occupant-related factors are treated as part of a sensitivity analysis which only requires the variation range of the parameters but not the whole annual behaviour pattern.

Based on these five uncertainty sources, the uncertainties in the parameters contained in each of the four categories can be defined and obtained. Design alternative is a general source which may bring in uncertainties to all the parameters, because if the designer changes the design then the values of the parameters are changed. Specification uncertainty applies to the parameters normally unspecified in the design, for example the leakage of the duct work. The other three uncertainty sources apply to specific parameters. The main parameters, uncertainties, dominant uncertainty sources and proposed estimation methods are summarised in Table 1 (design alternative is not mentioned in Table 1, because it is a general uncertainty source which applies to all the parameters). The list in Table 1 is considered to cover most of the uncertainties but is not exhaustive.

\subsection{Method to Deal with Uncertainties}

\subsubsection{Basic Uncertainty Quantification Techniques}

In uncertainty quantification studies, there are generally two different analysis purposes, i.e. quantification of the uncertainties in output resulting from uncertainties in inputs, and figuring out the individual influence or importance of each uncertainty on the outputs. These respective analysis techniques can be generally categorized as uncertainty propagation and sensitivity analysis. 
Table 1. Parameters, uncertainties, dominant uncertainty sources and relevant estimation methods.

\begin{tabular}{|c|c|c|}
\hline Parameters & Main uncertainty sources & Possible estimation methods \\
\hline \multicolumn{3}{|l|}{ Ventilation components } \\
\hline Geometry properties & Production deviation; & Estimation from measurement data; \\
\hline $\begin{array}{l}\text { Flow coefficients } \\
\text { \& Flow exponents } \\
\text { Duct leakage }\end{array}$ & $\begin{array}{l}\text { Production deviation; } \\
\text { Modelling uncertainties } \\
\text { Specification uncertainty; } \\
\text { Production deviation; }\end{array}$ & $\begin{array}{l}\text { Measurement or products data; } \\
\text { Measurement data and interactions; } \\
\text { Probable duct type or airtight levels; } \\
\text { Measurement data; }\end{array}$ \\
\hline Duct pressure loss change & Production deviation; & Assumptions based on measurement data; \\
\hline Exhaust/supply grilles & Construction deviation; & $\begin{array}{l}\text { Accuracy requirements on fittings; } \\
\text { Measurement data; }\end{array}$ \\
\hline Heat recovery efficiency & Production deviation; & Product information and measurement data; \\
\hline Internal leakage & Production deviation; & Product information and measurement data; \\
\hline \multicolumn{3}{|l|}{ Building properties } \\
\hline Building direction & Specification uncertainty; & Probable directions and design limitations; \\
\hline Building air tightness & $\begin{array}{l}\text { Specification uncertainty; } \\
\text { Construction deviation }\end{array}$ & $\begin{array}{l}\text { Specified air tightness level; } \\
\text { Measurement data. }\end{array}$ \\
\hline \multicolumn{3}{|l|}{ Outdoor environment } \\
\hline Climate data & Specification uncertainty; & Probable climate regions; \\
\hline wind reduction factor & $\begin{array}{l}\text { Stochastic process; } \\
\text { Modelling uncertainty }\end{array}$ & $\begin{array}{l}\text { Using different typical weather data; } \\
\text { Estimation from calculation models; } \\
\text { Expert judgment; }\end{array}$ \\
\hline Wind pressure coefficients & Modelling uncertainty & $\begin{array}{l}\text { Estimation from calculation models; } \\
\text { Expert judgment; }\end{array}$ \\
\hline wind direction & Modelling uncertainty & $\begin{array}{l}\text { Estimation between different climate data; } \\
\text { Expert suggestions; }\end{array}$ \\
\hline Local temperature & Modelling uncertainty & Estimation from literature or data; \\
\hline \multicolumn{3}{|l|}{ Occupant behaviour } \\
\hline Indoor temperature set-point & Specification uncertainty & Estimation from survey data; \\
\hline Control of air inlet & Stochastic process & Default occupant profile \\
\hline Control of windows & Stochastic process & Default occupant profile \\
\hline Control of doors & Stochastic process & Default occupant profile \\
\hline
\end{tabular}

For uncertainty propagation, many techniques exist including black box techniques (e.g. Monte-Carlo method), statistical methods (e.g. Factorial regressions), and internal methods (e.g. integrating uncertainties into the model equations). Among such techniques, we propose the Monte-Carlo method with Latin-hypercube sampling to be used for uncertainty propagation. The main reason for this selection is that the Monte-Carlo method does not require particular knowledge of statistics and is suitable for calculations with complex models or software packages and is widely applicable (Helton, 1993). Latin-hypercube sampling is a kind of improved stratified sampling method which divides each of the parameters into $\mathrm{N}$ disjoint intervals with equal probability mass. One value is randomly picked from each of the $\mathrm{N}$ intervals. Thus, $\mathrm{N}$ values are sampled for each uncertainty. Then, one value is randomly selected from the set of $\mathrm{N}$ values of each uncertainty. These are combined to be a sample set. This process is repeated $\mathrm{N}$ times and finally $\mathrm{N}$ sample sets are created. This technique could provide a good coverage of the parameter sample space with relatively small number of samples compared to random sampling (Iman and Helton, 1988). More detailed information about the Latinhypercube sampling method can be found in Mckay et al (1979).

Sensitivity analysis can be divided into different levels, from addressing the important or influential parameters to addressing the interaction between parameters and the quadratic influence of a single parameter. For uncertainty quantification studies in 
engineering, normally a parameter screening process is carried out first to determine the most influential parameters from a large set of parameters. For parameter screening, the Morris factorial sampling method is recommended. This method indicates which factors are important and also gives information on the directions of the effects, on the severity of parameter interactions or on nonlinear effects.

The Morris method can actually be viewed as a special application of the traditional one-factor-atone-time sensitivity analysis which measures the sensitivity by Equation 7:

$$
E\left(x_{i}\right)=\frac{f\left(x_{1}, x_{2}, \ldots, x_{i}+\Delta x_{i}, \ldots, x_{n}\right)-f\left(x_{1}, x_{2}, \ldots, x_{i}, \ldots, x_{n}\right)}{\Delta x_{i}}
$$

where:

$E\left(x_{i}\right)$ is normally called the main effect, and equals the sensitivity of the output to a change of input $x_{i}$; $f\left(x_{1}, x_{2}, \ldots, x_{i}, \ldots, x_{n}\right)$ is the value of the output when all inputs are set at the base values;

$f\left(x_{1}, x_{2}, \ldots, x_{i},+\Delta x_{i}, \ldots, x_{n}\right)$ is the value of the output when all inputs are set at the base values, except the value of the input $x_{i}$ which is changed by $\Delta x_{i}$.

The Morris method repeats this process $\mathrm{M}$ times. For each time, the base values are re-selected. M main effects (called the elementary effect in the Morris method) are obtained. The mean value and standard deviation of such $\mathrm{M}$ main effects are used for measuring the influence and interaction/ nonlinear effect of the input parameters in the Morris method. The higher the mean value, the more influential the relevant parameter is on the output. Also, the higher the standard deviation, the larger the parameter interactions/non-linear effect the relevant parameter is involved in. Finally, the Morris method is able to determine the potentially important parameters and the extent to which the non-linear effect and parameter interactions contribute to the influence of a parameter. A more detailed introduction into the Morris sampling method can be found in the article of Morris (1991).

\subsubsection{Simulation Process}

Although the analysis techniques are available in the literature, the detailed calculation process in relation to the development process of ventilation systems and the different kinds of uncertainties involved needs more discussion.
Treatment according to the status of the commissioning process

Generally speaking, the purpose of the commissioning process is to guarantee that the installed system works properly. In this respect one of the most important aspects to address is the mechanical flow rate at the supply/exhaust grilles. If the commissioning process is carried out properly, the influence of some uncertainties on the airflow rate at the exhaust/supply grilles will be eliminated or reduced. Thus, the status of the commissioning process may influence some calculation steps of the analysis. In practice, however, the commissioning process is not always properly carried out during the construction process. Three conditions may exist in practice:

- Case I: For an individual house, the commissioning process is carried out well;

- Case II: For a set of houses with the same floor plan and ventilation design, the commissioning process is carried out for only 1 or 2 typical buildings, after which the valve and fan settings are applied to the other buildings.

- Case III: The commissioning process is not carried out at all. The system is just assumed to operate according to the paper design.

Based on experience, it is likely that, in practice, Case II appears to be the most used method, especially when facing a set of similar houses. For these one or two typical houses, because the commissioning processes are well-conducted, the correct mechanical airflow rates are guaranteed. Subsequently, the determined fan position and exhaust/supply valves position settings are applied to other houses. However, in most of the houses, the required settings could be different from the typical/ commissioned houses, including the duct pressure loss, the duct leakage, the internal leakage and the fan curve. Due to such variations, the position of the fans and the valve settings resulting from the commissioned systems may bring variations into the mechanical airflow rates.

For this kind of situation, the calculation process should be as follows:

- For the uncertainties related to the mechanical ducted systems, including duct pressure loss, ductwork leakage and internal leakage, a base case for these parameters must be determined and flow balance must be reached. Such a base case can be chosen as the mean value of the 
parameters or can be randomly chosen based on the variation ranges of the parameters

- Based on the balanced case (base case), the variations can be made and the uncertainty analysis can be carried out

- Afterwards, if the outputs show significant variations, then a sensitivity analysis (parameter screening analysis) should be carried out to identify the most important parameters/ uncertainties.

In the above context, methods to carry out the uncertainty analysis based on different situations of the commissioning process are described. One argument could be whether the status of the commissioning process should be considered as an uncertainty. For this point, the opinion taken is that the commissioning process can be viewed as an uncertainty but should be separately analysed for each possible variation.

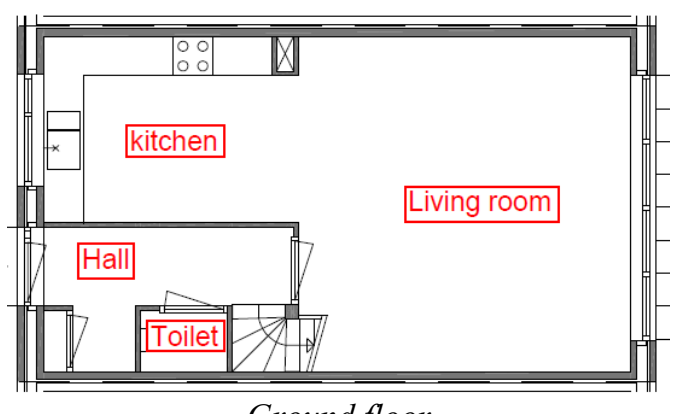

Ground floor

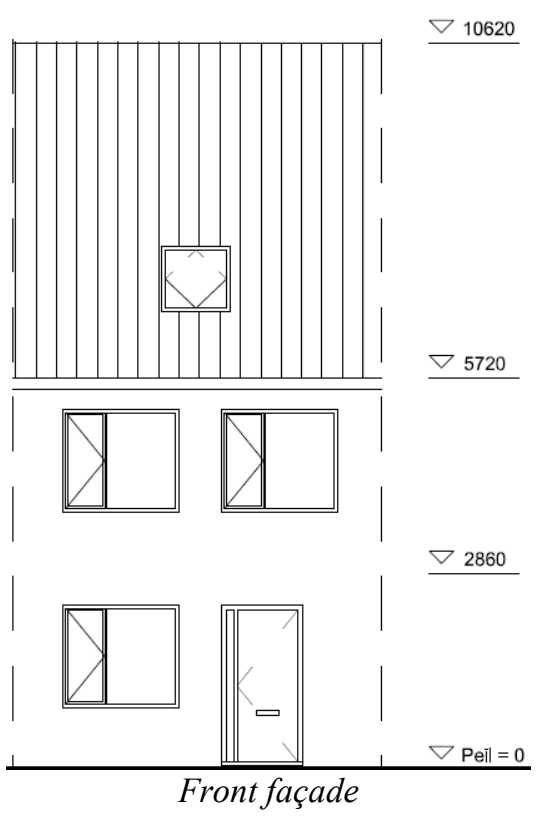

\section{Case Study}

\subsection{Case Study Dwelling}

To show the application of this assessment method, a case study was carried out on a HRVS with a counter flow heat exchanger in a typical Dutch three storey house. The floor plan and façade view of the house are shown in Figure 1. The dwelling is assumed to be located in Delft in the Netherlands; it is identical to the reference Dutch single family house from Agentschap NL (mid terraced dwelling).

\subsection{Identification of Criteria}

After the introduction of the basic case information, the first step is to identify the detailed criteria and required values based on the design regulations. Combining the criteria defined in Section 2 and the case information, the criteria and relevant required values to be used are summarized in Table 2 .
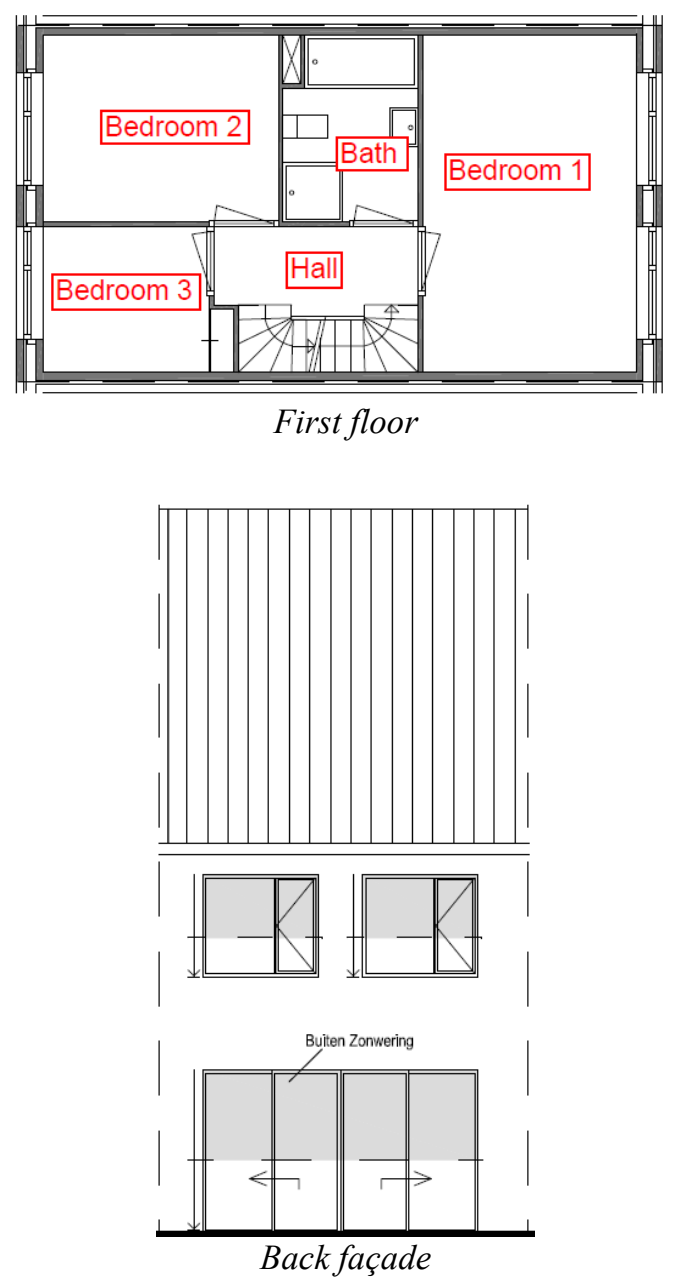

Figure 1. Floor plans and façades of the reference building. 
Table 2. Summarization of criteria and required values.

\begin{tabular}{llll}
\hline Category & Criterion & \multicolumn{2}{l}{ Required value } \\
Air flow & Exhaust rate in kitchen & $33.4 \mathrm{dm}^{3} / \mathrm{s}$ & $(120.2 \mathrm{~m} 3 / \mathrm{h})$ \\
& Exhaust rate in toilet & $7 \mathrm{dm} 3 / \mathrm{s}$ & $(25.2 \mathrm{~m} 3 / \mathrm{h})$ \\
& Exhaust rate in bathroom & $14 \mathrm{dm} 3 / \mathrm{s}$ & $(50.4 \mathrm{~m} 3 / \mathrm{h})$ \\
& Total house exhaust rate & $54.4 \mathrm{dm} 3 / \mathrm{s} \quad(195.8 \mathrm{~m} 3 / \mathrm{h})$ \\
& Supply rate in living room & $23.4 \mathrm{dm} 3 / \mathrm{s} \quad(84.2 \mathrm{~m} 3 / \mathrm{h})$ \\
& Supply rate in bedroom 1 & $14.7 \mathrm{dm} 3 / \mathrm{s} \quad(52.9 \mathrm{~m} 3 / \mathrm{h})$ \\
& Supply rate in bedroom 2 & $9.3 \mathrm{dm} 3 / \mathrm{s} \quad(33.5 \mathrm{~m} 3 / \mathrm{h})$ \\
& Supply rate in bedroom 3 & $7 \mathrm{dm} 3 / \mathrm{s}$ & $(25.2 \mathrm{~m} 3 / \mathrm{h})$ \\
& Total house supply rate & $54.4 \mathrm{dm} 3 / \mathrm{s} \quad(195.8 \mathrm{~m} 3 / \mathrm{h})$ \\
& Unwanted air flow direction & $0 \%$ & \\
\hline Energy & Net energy saved & $/$ & \\
\hline
\end{tabular}

Table 3. Uncertainties, variation ranges and distribution.

\begin{tabular}{|c|c|c|c|c|}
\hline Parameters & $\begin{array}{l}\text { Variation } \\
\text { range }\end{array}$ & $\begin{array}{l}\text { Probability } \\
\text { function }\end{array}$ & Unit & Estimation basis \\
\hline window leakage & $(0.086,0.41)$ & Normal & $\mathrm{dm}^{3} /\left(\right.$ s.m.pa $\left.{ }^{-\mathrm{n}}\right)$ & AIVC GUIDE 05 \\
\hline Window frame leakage & $(0.00033,0.012)$ & Normal & $\mathrm{dm}^{3} /\left(\right.$ s.m.pa $\left.{ }^{-\mathrm{n}}\right)$ & \\
\hline Internal door leakage & $(1.1,2)$ & Normal & $\mathrm{dm}^{3} /\left(\right.$ s.m.pa $\left.{ }^{-\mathrm{n}}\right)$ & \\
\hline External door leakage & $(0.082,0.84)$ & Normal & $\mathrm{dm}^{3} /\left(\right.$ s.m.pa $\left.{ }^{-\mathrm{n}}\right)$ & \\
\hline Facade leakage & $(0.016,0.021)$ & Normal & $\mathrm{dm}^{3} /\left(\mathrm{s} \cdot \mathrm{m}^{2} \cdot \mathrm{pa}^{-\mathrm{n}}\right)$ & \\
\hline $\begin{array}{l}\text { Leakage through the } \\
\text { joint wall/ ceiling }\end{array}$ & $(0.005,0.11)$ & Normal & $\mathrm{dm}^{3} /\left(\right.$ s.m.pa $\left.{ }^{-\mathrm{n}}\right)$ & \\
\hline Roof leakage & $(0.6,1.1)$ & Normal & $\mathrm{dm}^{3} /\left(\mathrm{s} \cdot \mathrm{m}^{2} \cdot \mathrm{pa}^{-\mathrm{n}}\right)$ & \\
\hline Duct leakage & $\begin{array}{ll}(0.009, & 0.054) \\
10^{-3} & \end{array}$ & Normal & $\mathrm{dm}^{3} /\left(\mathrm{s} \cdot \mathrm{m}^{2} \cdot \mathrm{pa}^{0.65}\right)$ & LUKA classes, assumptions; \\
\hline Exhaust/supply grilles & $(-10 \%, 10 \%)$ & Normal & (c) & $\begin{array}{l}\text { Based on the recommendation } \\
\text { of ISSO. }\end{array}$ \\
\hline $\begin{array}{ll}\text { Heat } & \text { recovery } \\
\text { efficiency } & \end{array}$ & $(70 \%, 90 \%)$ & Normal & / & $\begin{array}{l}\text { Literature about product } \\
\text { information and estimation; }\end{array}$ \\
\hline Internal leakage & $(0,0.0001)$ & Normal & $\mathrm{kg} /\left(\mathrm{s} . \mathrm{pa}^{0.65}\right)$ & $\begin{array}{l}\text { Some measurement data and } \\
\text { inquiry; }\end{array}$ \\
\hline $\begin{array}{l}\text { Duct pressure loss } \\
\text { change }\end{array}$ & $(-20 \%, 20 \%)$ & Normal & / & Assumption; \\
\hline $\begin{array}{l}\text { Terrain roughness } \\
\text { (wind reduction factor) }\end{array}$ & $(0.25,0.4)$ & Uniform & / & $\begin{array}{l}\text { Based on the definitions in the } \\
\text { manual and literature; }\end{array}$ \\
\hline $\begin{array}{l}\text { Wind } \\
\text { coefficients }\end{array}$ & $(-10 \%, 10 \%)$ & Uniform & l & $\begin{array}{l}\mathrm{Cp} \text {-generator and estimation } \\
\text { from the empirical accuracy of } \\
\mathrm{Cp} \text {-generator }\end{array}$ \\
\hline Local temperature & $(0,1)$ & Uniform & ${ }^{\circ} \mathrm{C}$ & Literature and assumptions. \\
\hline $\begin{array}{l}\text { Indoor temperature set- } \\
\text { point }\end{array}$ & $\begin{array}{l}(12,21) \text { daytime } \\
(14,21) \text { evening } \\
(10,19) \text { night }\end{array}$ & Normal & ${ }^{\circ} \mathrm{C}$ & Estimation from survey data; \\
\hline
\end{tabular}

(Note: Duct pressure loss change means the deviation of actual pressure loss of the ductwork from the values of the commissioned case. The whole house leakage under the mean values of the component leakages is around $0.1 \mathrm{~m} 3 / \mathrm{s}$ at $10 \mathrm{~Pa}$ 


\subsection{Identification of Uncertainties}

The identification of the uncertainties is based on the methods described in Section 3. The uncertainties considered, the estimated variation range, assigned distribution functions and relevant estimation method are summarized in Table 3.

The default occupant behaviour profile related to the use of windows, doors and fan was used, i.e. doors and windows are assumed to be closed and the fan is always running at the designed position throughout the whole calculation period.

This profile may not be in accordance with occupant behaviour profiles in practice. The system performance under our occupant behaviour profile can be viewed as a pure performance of the system which reflects the capability of this system to provide the designed performance.

\subsection{Modelling and Calculations}

Before actual calculations can be performed, the ventilation model must be built and tested for simulation. The model use was the building simulation software TRNFLOW which is a combination with TRNSYS and COMIS. The main advantage of TRNSYS is that it can deal with the interaction between the airflow behaviour and temperature changes without heavy iterative calculation work.
The house was divided into 11 zones, with these zones being connected with each other by links, such as cracks (internal leakage) and openings (internal doors). This linkage is shown in Figure 2. The internal leakage was assumed to be located at mid-height of the wall.

The ducted mechanical balanced ventilation system was also modelled as shown in Figure 3. The duct leakage was modelled as a link between the duct and the indoor space. The ventilation unit with the heat exchanger was located in the attic. The sum of the exhaust airflow (at node 01) and the supply airflow (at node S0) passes through the heat exchanger, the resulting temperatures and airflow rates are inputted into the node exh (leaving the building) and node sph (supply to habitable space).

The heating system was modelled in TRNSYS as a radiator with limited heating power.

\subsubsection{Model Validation}

The best validation of the model is direct comparison of the model outputs with comparable measurement data. Unfortunately, there is no such measurement data available for the current model. In order to check that the model was correctly modelled in principal, several tests including the components' flow characteristics, system pressure loss balance and stack effect were carried out. All the simulation results related to such aspects were in

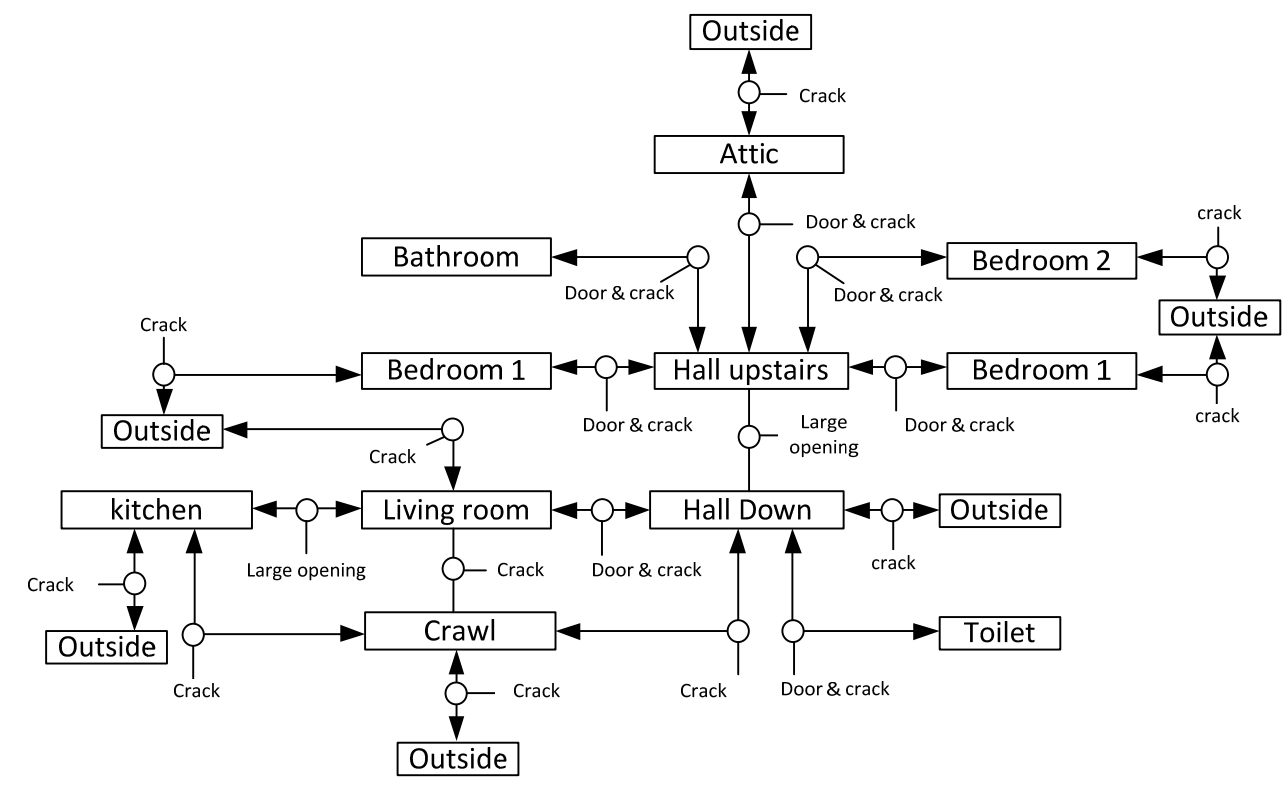

Figure 2. Linkage of the zones in the calculation model. 


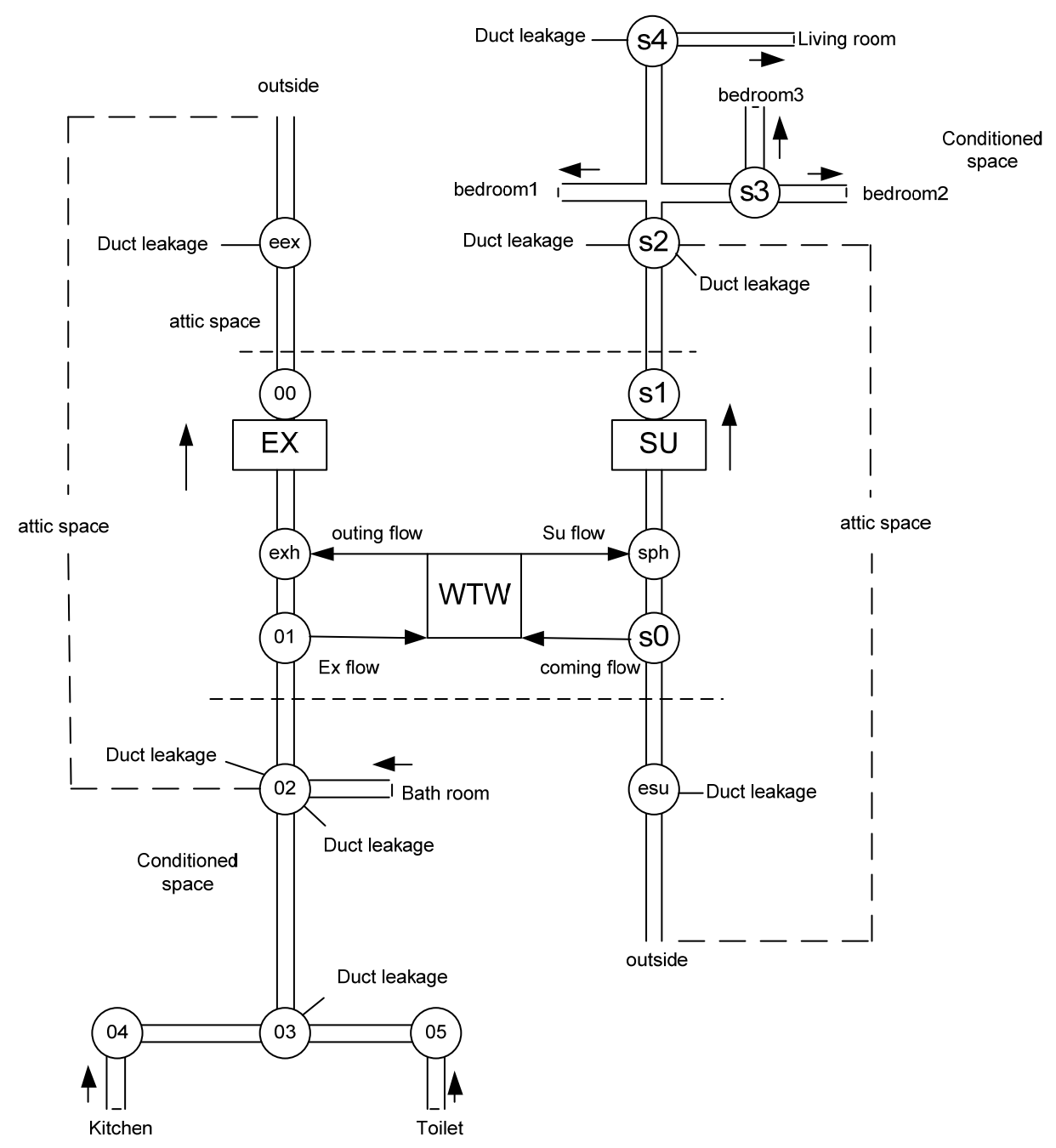

Figure 3. Linkage of the ducted balanced ventilation system.

accordance with the results obtained by the underlying equations and laws, for example, the pressure difference between the air inlets on the $1^{\text {st }}$ floor and the ground floor resulting from the stack effect in the calculation model is comparable to the result obtained from an empirical equation; the total pressure loss of every closed flow circle equals to zero (Kirchhoff's circuit laws); the total incoming airflow rates equal the total leaving airflow rates in every room and the whole house.

\subsubsection{Uncertainty Propagation}

140 sample sets were generated using the Latinhypercube sampling method, which is 5 times the number of parameters (28). This number is much larger than the proposed (according to deWit (2002), referring to Iman and Helton (1985)) minimum number $4 / 3 \mathrm{k}$ ( $\mathrm{k}$ is the number of parameters), which can be considered to be adequate.

\subsubsection{Sensitivity Analysis}

116 sample sets were generated using the Morris Factorial sampling method for parameter screening analysis.

\subsection{Results}

\subsubsection{Uncertainty Propagation Results}

After the execution of 140 simulation runs, the results were sorted and analysed as follows:

\section{Average hourly exhaust and supply airflow rates}

The airflow rates at 7 locations were considered: i.e. the exhaust airflow rates in the kitchen, the bathroom and the toilet, and the supply airflow rates in the living room, bedroom 1, bedroom 2 and bedroom 3. The results are shown in Figure 4. 


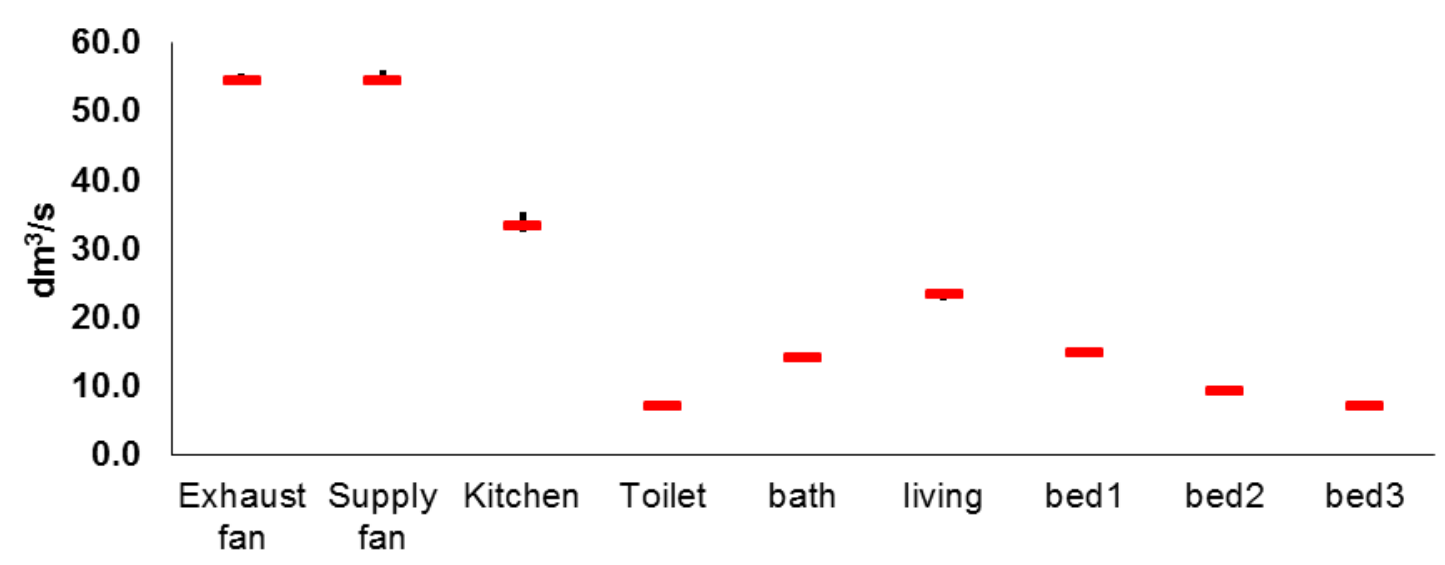

Air flow locations

Figure 4. Average hourly airflow rates of the mechanical exhaust and supply.

(Note: For 'Kitchen, Toilet, Bathroom', the airflow rates are the mechanical exhaust airflow rates; for 'living room, bedroom 1, 2 and 3', the airflow rates are the mechanical supply airflow rates.)

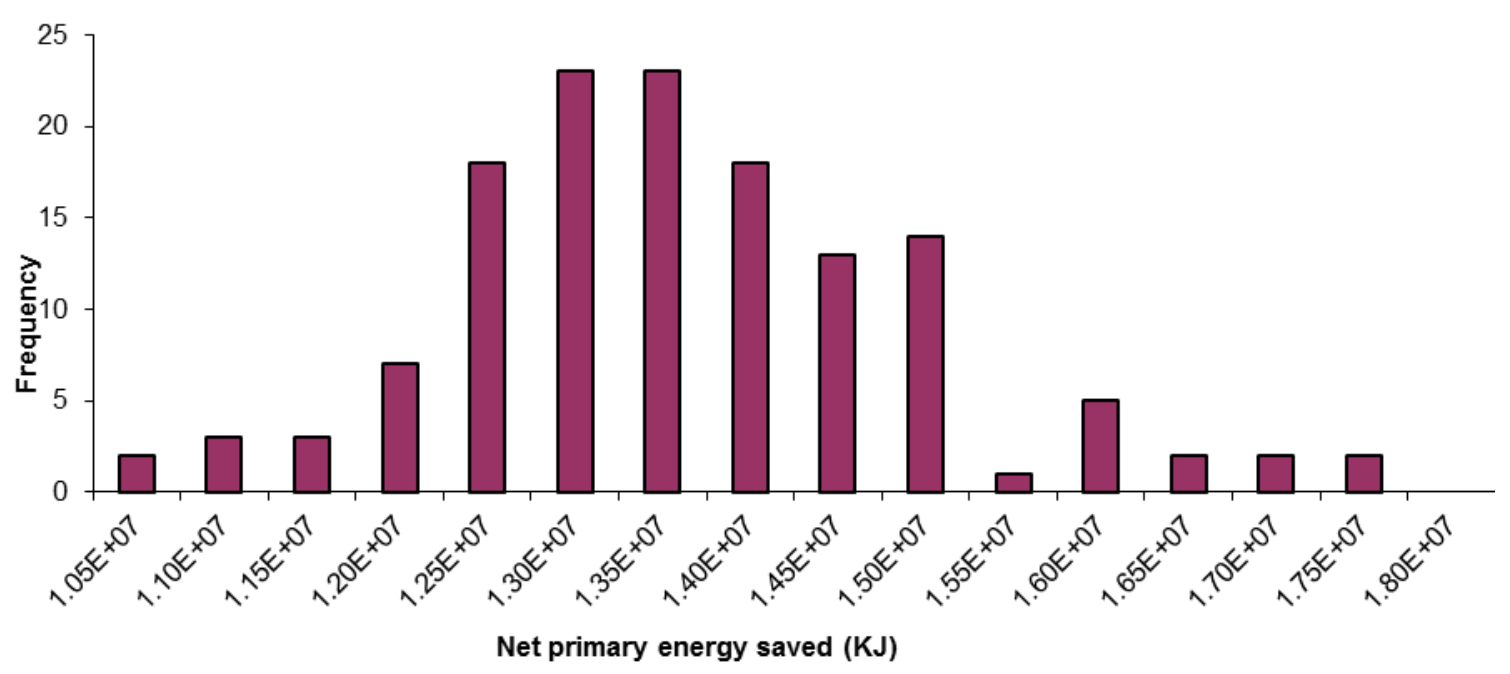

Figure 5. Frequency distribution of the net primary energy saved ( $\mathrm{kJ})$.

From the results, it can be seen that the mean values of the average hourly airflow rates are all close to the designed values with small variations.

\section{Unwanted airflow directions}

From the simulation, no occurrence of airflows with unwanted direction, i.e. airflow from polluted rooms (toilet and bathroom) to habitable space (hall), was found.

\section{Unwanted recirculation rates}

From the simulation, the recirculation rate (from exhaust to supply) was found to vary from $0.5 \%$ to $7.1 \%$ with a mean value of $4.5 \%$.
Net energy saved (NES) (primary energy)

For calculating the NES, two values were used, i.e. the NES throughout the whole year and the NES during the heating season. In this latter value the data of July, August and September were excluded because there might be the situation that the heating system is turned off during summer although during some hours the indoor temperature is lower than the set-point temperature. The mean value of the NES throughout the whole year is $1.39 \times 10^{7} \mathrm{~kJ}$, while the mean value of the NES of the heating period is $9.96 \times 10^{6} \mathrm{~kJ}$. The frequency distribution of the NES throughout the whole year is shown in Figure 5. 


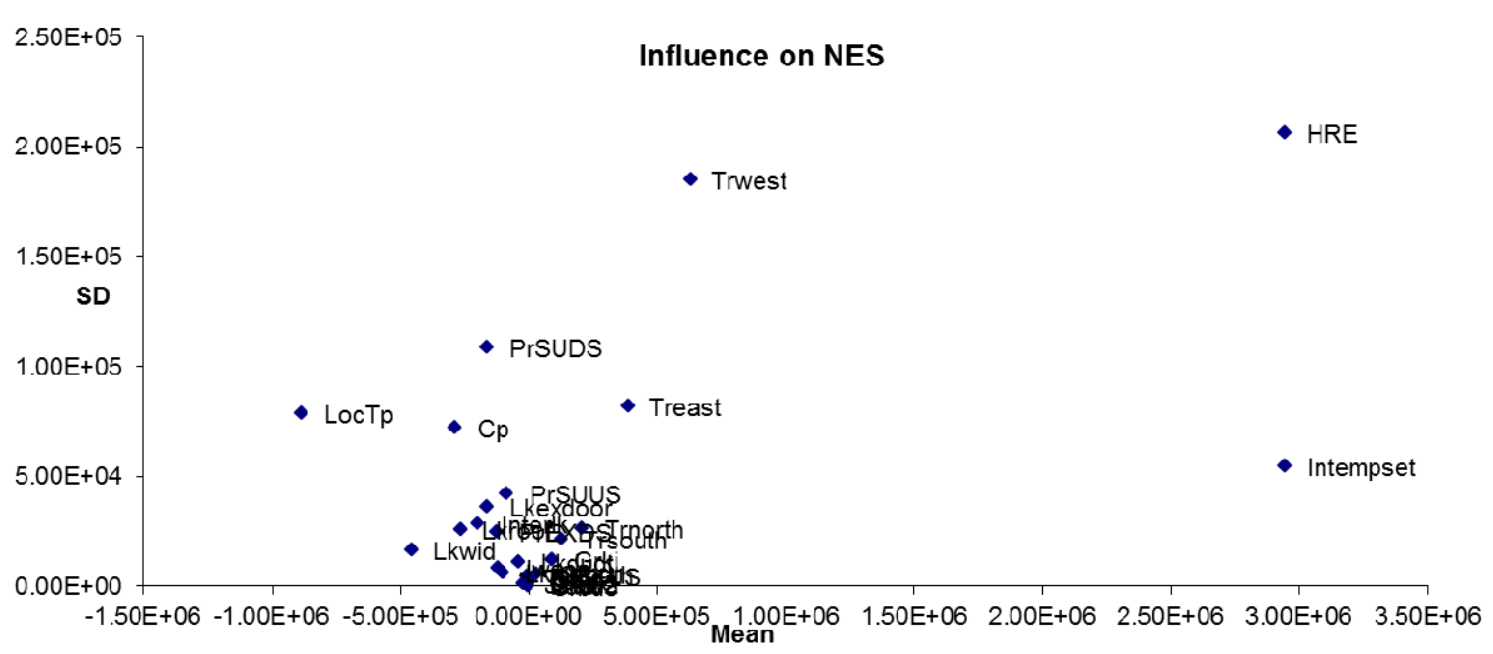

(Note: the explanations for all the abbreviations are summarized in Table 5).

Figure 6. Influence of each parameter on the NET.

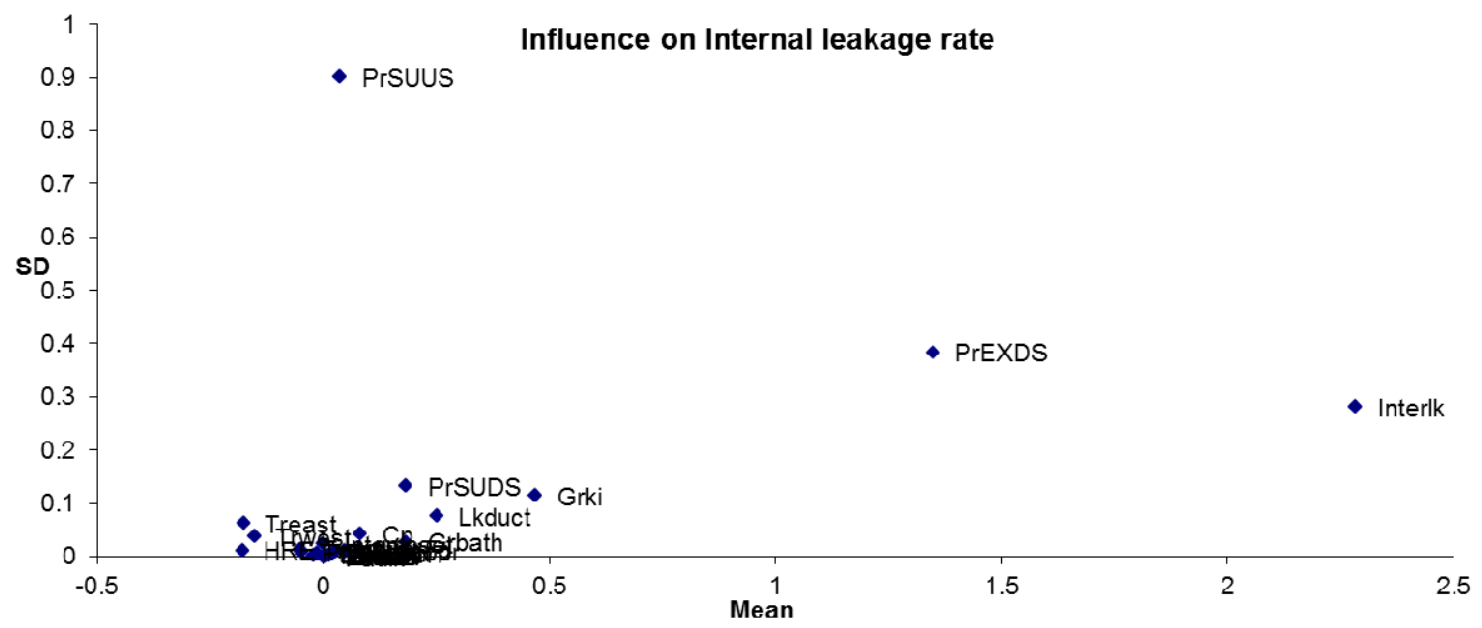

Figure 7. Influence of each parameter on internal leakage rate.

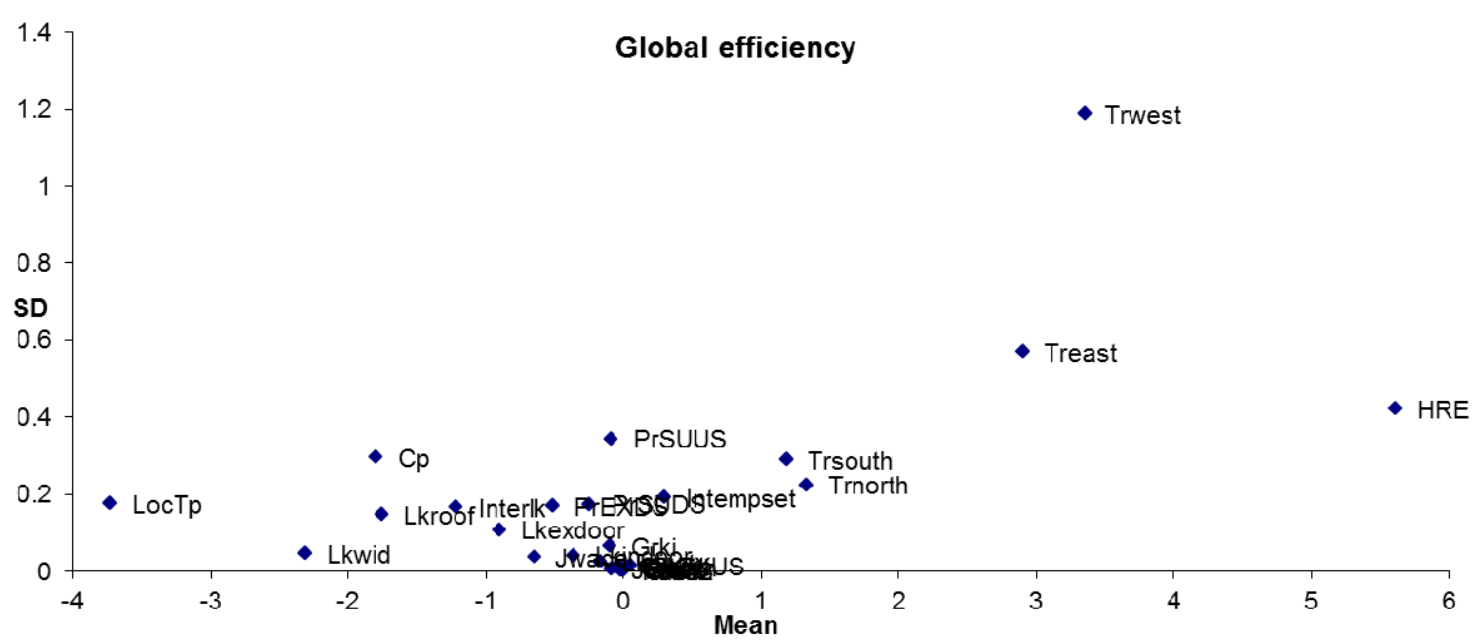

Figure 8. Influence of each parameter on global efficiency. 
Table 4. Explanations for the abbreviations in Figures 6,7 and 8.

\begin{tabular}{|c|c|}
\hline Abbreviations & Explanation \\
\hline Fadlk & Leakage of façade, $\mathrm{dm}^{3} /\left(\mathrm{s} \cdot \mathrm{m}^{2} \cdot \mathrm{pa}^{-\mathrm{n}}\right)$ \\
\hline Jwace & Leakage of joint between wall and ceiling/floor, $\mathrm{dm}^{3} /\left(\right.$ s.m.pa $\left.{ }^{-\mathrm{n}}\right)$ \\
\hline Lkwind & Leakage of window, $\mathrm{dm}^{3} /\left(\right.$ s.m.pa $\left.{ }^{-\mathrm{n}}\right)$ \\
\hline Lkexdoor & Leakage of external door, $\mathrm{dm}^{3} /\left(\right.$ s.m.pa $\left.{ }^{-n}\right)$ \\
\hline Jfrawa & Leakage of joint between door/ window frame with wall, $\mathrm{dm}^{3} /\left(\mathrm{s} . \mathrm{m} \cdot \mathrm{pa}^{-\mathrm{n}}\right)$ \\
\hline Lkroof & Leakage of roof, $\mathrm{dm}^{3} /\left(\mathrm{s} \cdot \mathrm{m}^{2} \cdot \mathrm{pa}^{-\mathrm{n}}\right)$ \\
\hline Lkduct & Leakage of ductwork, $\mathrm{dm}^{3} /\left(\mathrm{s} \cdot \mathrm{m}^{2} \cdot \mathrm{pa}^{0.65}\right)$ \\
\hline Grki & Deviation of position of exhaust grille compared to designed value in kitchen, $\%$ \\
\hline Grbath & Deviation of position of exhaust grille compared to designed value in bathroom, $\%$ \\
\hline Grtoi & Deviation of position of exhaust grille compared to designed value in toilet, $\%$ \\
\hline Grlv & Deviation of position of supply grille compared to designed value in livingroom, $\%$ \\
\hline Grbd1 & Deviation of position of supply grille compared to designed value in bedroom $1, \%$ \\
\hline Grbd2 & Deviation of position of supply grille compared to designed value in bedroom $2, \%$ \\
\hline Grbd3 & Deviation of position of supply grille compared to designed value in bedroom $3, \%$ \\
\hline Loctp & Difference between the local temperature and the meteorological temperature, $\mathrm{K}$ \\
\hline Intempset & Indoor temperature setting pattern, - \\
\hline PrEXUS & Pressure change of the upstream air flow (before the fan) of exhaust routine, $\%$ \\
\hline PrEXDS & Pressure change of the downstream air flow (after the fan) of exhaust routine, $\%$ \\
\hline PrSUUS & Pressure change of the upstream air flow (before the fan) of supply routine, $\%$ \\
\hline PrSUDS & Pressure change of the downstream air flow (after the fan) of supply routine, $\%$ \\
\hline Interlk & Internal leakage (between exhaust and supply routines), $\mathrm{kg} /\left(\mathrm{s} . \mathrm{pa}^{0.65}\right)$ \\
\hline HRE & Heat recovery efficiency of the heat exchanger, $\%$ \\
\hline Trnorth & Terrain roughness of the north direction, - \\
\hline Trsouth & Terrain roughness of the south direction, - \\
\hline Treast & Terrain roughness of the east direction, - \\
\hline Trwest & Terrain roughness of the west direction, - \\
\hline $\mathrm{Cp}$ & Variation of the actual wind pressure coefficient compared to the calculated values, $\%$ \\
\hline
\end{tabular}

\section{Global recovery efficiency}

Similar to the net energy recovered, calculation of the global recovery efficiency also considers two different situations, i.e. the whole year and the heating season (excluding July, August and September). The results show that there is little difference between these two values. The mean value of the global recovery efficiency is $46 \%$, with a variation range $(41 \%, 55 \%)$ and a standard deviation of $3 \%$.

\subsubsection{Sensitivity Analysis Results}

The sensitivity analysis (parameter screening) was carried out for the unwanted recirculation rate, the net energy recovered and the global recovery efficiency which display the greatest variations in the uncertainty propagation. The results including the relative importance of each parameter (mean of the elementary effects) and the interactions of the parameter with other parameters (standard deviation of the elementary effects, SD) are shown in Figures 6, 7 and 8, and Table 5. All the explanations of the abbreviations are displayed in Table 4.

From the figures, the following can be derived:

- For the net energy saved, the most influential parameter is the indoor set-point temperature (Intempset) while the heat exchange efficiency of the heat exchanger (HRE) appears to be the second most important parameter;

- For the unwanted internal leakage, the most important parameter is the leakage value on the heat exchange plate (Interlk), while the second most influential parameter is the duct pressure loss change of the downstream part of the exhaust routine (PrEXDS); 
Table 5, Standard deviation (SD) and mean value of the elementary effects of the uncertainties.

\begin{tabular}{|c|c|c|c|c|c|c|c|c|}
\hline \multicolumn{3}{|c|}{$\begin{array}{l}\text { For NES (kJ) } \\
\text { (Figure 6) }\end{array}$} & \multicolumn{3}{|c|}{$\begin{array}{l}\text { For internal leakage rate (\%) } \\
\text { (Figure 7) }\end{array}$} & \multicolumn{3}{|c|}{$\begin{array}{l}\text { For global efficiency (\%) } \\
\text { (Figure 8) }\end{array}$} \\
\hline Parameter & mean & SD & Parameter & mean & SD & Parameter & mean & SD \\
\hline Intempset & $2.9 \mathrm{E}+06$ & $5.5 \mathrm{E}+04$ & Interlk & $2.3 \mathrm{E}+00$ & $2.8 \mathrm{E}-01$ & HRE & $5.6 \mathrm{E}+00$ & $4.2 \mathrm{E}-01$ \\
\hline HRE & $2.9 \mathrm{E}+06$ & $2.1 \mathrm{E}+05$ & PrEXDS & $1.3 \mathrm{E}+00$ & $3.8 \mathrm{E}-01$ & LocTp & $-3.7 \mathrm{E}+00$ & $1.8 \mathrm{E}-01$ \\
\hline LocTp & $-8.8 \mathrm{E}+05$ & $7.9 \mathrm{E}+04$ & Grki & 4.7E-01 & $1.1 \mathrm{E}-01$ & Trwest & $3.4 \mathrm{E}+00$ & $1.2 \mathrm{E}+00$ \\
\hline Trwest & $6.3 \mathrm{E}+05$ & $1.8 \mathrm{E}+05$ & Lkduct & $2.5 \mathrm{E}-01$ & 7.6E-02 & Treast & $2.9 \mathrm{E}+00$ & $5.7 \mathrm{E}-01$ \\
\hline Lkwind & $-4.5 \mathrm{E}+05$ & $1.7 \mathrm{E}+04$ & Grbath & $1.8 \mathrm{E}-01$ & $2.8 \mathrm{E}-02$ & Lkwind & $-2.3 \mathrm{E}+00$ & 4.7E-02 \\
\hline Treast & $3.9 \mathrm{E}+05$ & $8.2 \mathrm{E}+04$ & PrSUDS & $1.8 \mathrm{E}-01$ & $1.3 \mathrm{E}-01$ & $\mathrm{Cp}$ & $-1.8 \mathrm{E}+00$ & $3.0 \mathrm{E}-01$ \\
\hline $\mathrm{Cp}$ & $-2.8 \mathrm{E}+05$ & $7.2 \mathrm{E}+04$ & HRE & $-1.8 \mathrm{E}-01$ & $1.2 \mathrm{E}-02$ & Lkroof & $-1.8 \mathrm{E}+00$ & $1.5 \mathrm{E}-01$ \\
\hline Lkroof & $-2.6 \mathrm{E}+05$ & $2.6 \mathrm{E}+04$ & Treast & $-1.7 \mathrm{E}-01$ & $6.3 \mathrm{E}-02$ & Trnorth & $1.3 \mathrm{E}+00$ & 2.3E-01 \\
\hline Trnorth & $2.1 \mathrm{E}+05$ & $2.6 \mathrm{E}+04$ & Trwest & $-1.5 \mathrm{E}-01$ & $3.8 \mathrm{E}-02$ & Interlk & $-1.2 \mathrm{E}+00$ & $1.7 \mathrm{E}-01$ \\
\hline Interlk & $-1.9 \mathrm{E}+05$ & $2.8 \mathrm{E}+04$ & $\mathrm{Cp}$ & $8.3 \mathrm{E}-02$ & $4.3 \mathrm{E}-02$ & Trsouth & $1.2 \mathrm{E}+00$ & $2.9 \mathrm{E}-01$ \\
\hline PrSUDS & $-1.6 \mathrm{E}+05$ & $1.1 \mathrm{E}+05$ & LocTp & $8.0 \mathrm{E}-02$ & $1.4 \mathrm{E}-02$ & Lkexdoor & $-9.0 \mathrm{E}-01$ & $1.1 \mathrm{E}-01$ \\
\hline Lkexdoor & $-1.6 \mathrm{E}+05$ & $3.6 \mathrm{E}+04$ & Trsouth & $-4.9 \mathrm{E}-02$ & $1.4 \mathrm{E}-02$ & Jwace & $-6.5 \mathrm{E}-01$ & 3.7E-02 \\
\hline Trsouth & $1.3 \mathrm{E}+05$ & $2.1 \mathrm{E}+04$ & PrEXUS & $-4.9 \mathrm{E}-02$ & $8.6 \mathrm{E}-03$ & PrEXDS & $-5.1 \mathrm{E}-01$ & $1.7 \mathrm{E}-01$ \\
\hline PrEXDS & $-1.2 \mathrm{E}+05$ & $2.5 \mathrm{E}+04$ & Grtoi & $4.8 \mathrm{E}-02$ & $1.0 \mathrm{E}-02$ & Lkindoor & $-3.7 \mathrm{E}-01$ & 4.3E-02 \\
\hline Jwace & $-1.2 \mathrm{E}+05$ & $8.5 \mathrm{E}+03$ & Lkwind & $4.8 \mathrm{E}-02$ & $8.4 \mathrm{E}-03$ & Intempset & $3.0 \mathrm{E}-01$ & $1.9 \mathrm{E}-01$ \\
\hline Lkindoor & $-9.6 \mathrm{E}+04$ & $6.4 \mathrm{E}+03$ & PrSUUS & $3.7 \mathrm{E}-02$ & $9.0 \mathrm{E}-01$ & PrSUDS & $-2.5 \mathrm{E}-01$ & $1.7 \mathrm{E}-01$ \\
\hline Grki & $9.3 \mathrm{E}+04$ & $1.2 \mathrm{E}+04$ & Lkexdoor & $2.7 \mathrm{E}-02$ & $1.0 \mathrm{E}-02$ & Lkduct & $-1.7 \mathrm{E}-01$ & $2.6 \mathrm{E}-02$ \\
\hline PrSUUS & $-8.3 \mathrm{E}+04$ & $4.2 \mathrm{E}+04$ & Trnorth & $-2.0 \mathrm{E}-02$ & $3.3 \mathrm{E}-03$ & Grki & $-1.0 \mathrm{E}-01$ & $6.5 \mathrm{E}-02$ \\
\hline Lkduct & $-3.8 \mathrm{E}+04$ & $1.1 \mathrm{E}+04$ & Grbd1 & $1.8 \mathrm{E}-02$ & 4.7E-03 & Jfrawa & $-9.1 \mathrm{E}-02$ & $6.2 \mathrm{E}-03$ \\
\hline Grbath & $3.3 \mathrm{E}+04$ & $5.7 \mathrm{E}+03$ & Jwace & $1.4 \mathrm{E}-02$ & $3.5 \mathrm{E}-03$ & PrSUUS & $-8.8 \mathrm{E}-02$ & $3.5 \mathrm{E}-01$ \\
\hline Jfrawa & $-1.9 \mathrm{E}+04$ & $1.4 \mathrm{E}+03$ & Lkindoor & $-1.4 \mathrm{E}-02$ & $5.9 \mathrm{E}-03$ & PrEXUS & 4.9E-02 & $1.5 \mathrm{E}-02$ \\
\hline PrEXUS & $-5.1 \mathrm{E}+03$ & $4.7 \mathrm{E}+03$ & Grlv & $1.2 \mathrm{E}-02$ & $2.0 \mathrm{E}-03$ & Grbd1 & $-4.6 \mathrm{E}-02$ & $1.4 \mathrm{E}-02$ \\
\hline Grlv & $4.7 \mathrm{E}+03$ & $3.5 \mathrm{E}+03$ & Grbd3 & $5.8 \mathrm{E}-03$ & $1.4 \mathrm{E}-03$ & Grbath & $-2.9 \mathrm{E}-02$ & $1.2 \mathrm{E}-02$ \\
\hline Fadlk & $-4.4 \mathrm{E}+03$ & $6.5 \mathrm{E}+02$ & Lkroof & $4.8 \mathrm{E}-03$ & $1.7 \mathrm{E}-03$ & Fadlk & $-2.3 \mathrm{E}-02$ & $3.8 \mathrm{E}-03$ \\
\hline Grtoi & $-1.7 \mathrm{E}+03$ & $2.4 \mathrm{E}+03$ & Grbd2 & $3.7 \mathrm{E}-03$ & 9.7E-04 & Grtoi & $-1.8 \mathrm{E}-02$ & $6.0 \mathrm{E}-03$ \\
\hline Grbd2 & $9.9 \mathrm{E}+02$ & $1.2 \mathrm{E}+03$ & Jfrawa & $1.7 \mathrm{E}-03$ & $7.0 \mathrm{E}-04$ & Grlv & 7.3E-03 & $6.0 \mathrm{E}-03$ \\
\hline Grbd3 & $8.9 \mathrm{E}+02$ & $4.9 \mathrm{E}+02$ & Intempset & $-1.5 \mathrm{E}-03$ & $2.5 \mathrm{E}-02$ & Grbd3 & $-3.4 \mathrm{E}-03$ & $2.2 \mathrm{E}-03$ \\
\hline Grbd1 & $-4.8 \mathrm{E}+02$ & $4.6 \mathrm{E}+03$ & Fadlk & $6.5 \mathrm{E}-04$ & 9.3E-05 & Grbd2 & $-2.6 \mathrm{E}-03$ & 2.7E-03 \\
\hline
\end{tabular}

- In the case of global efficiency, the most important parameter is the heat recovery efficiency of the heat exchanger (HRE), while the terrain roughness of the west and east direction (Trwest and Treast) are shown as the second and third most important parameters.

\subsection{Analysis and Discussion}

In the previous section, the results were shown for different aspects, each of which will be discussed briefly below.

\subsubsection{Airflow Rates Performance}

From the results, it was found that the exhaust/ supply airflow rates are steady and generally qualified. This result can be considered as reasonable because the airflows are provided by mechanical means. This result may, however, be too optimistic compared to the results found in practice. This can be explained by the fact that the uncertainties considered do not take the malfunction rate and deterioration during the usage phase into account.

\section{Air quality performance}

The airflow direction performance is also above expectation as no unwanted airflow directions were found. This result only covers the condition that the internal doors are closed.

The internal leakage rate is also within expectation as the uncertainty is adopted from the assumption that the internal leakage rate is within $(0,10 \%)$. The lack of practical data in usable form is a problem here. Internal leakage will reduce the supply air quality, and the highest internal leakage rate was 
found to be about $7.1 \%$, which is significant. In the sensitivity analysis, besides the leakage value of the internal crack, the pressure loss change of the ductwork also appears to be significant because the pressure loss change of the ductwork will influence the pressure difference across internal cracks. In the design, therefore, the importance of this pressure loss among the downstream and upstream of both the supply and exhaust side should be considered.

\subsubsection{Energy Related Performance}

The results show that the employment of the heat recovery appliance may be always preferred as the net primary energy benefit is positive in all calculated cases. In practice, the value of the net primary energy saved may be lower due to the actual operation mode of the mechanical system in practice. This may be different from the one specified in the default occupant profile. Significant variation is found in the results of the net primary energy saved. The indoor heating set-point temperature and the heat recovery efficiency of the heat exchanger appear to be the most and second most influential parameters. This result is not surprising.

The global efficiency results show that about half of the total energy loss due to air change was not recovered. This part is thought to result from infiltration and the actual efficiency limitation of the heat exchanger. Parameter screening analysis shows that the most important parameters are the efficiency of the heat exchanger and the terrain roughness substantiating that this might indeed be the case.

Above all, the results give an overview of the performance of the counter-flow heat recovery mechanical ventilation system which appears to be quite promising. The biggest concern about these results may be regarding the actual operation mode of the system and the actual properties of the house. These can be quite different from the default operation mode used in the current calculation. The results, however, do indicate to a certain extent the possible performance range and the important points to be considered during the design.

\section{Discussion and Limitations}

In above context, the method was described and further applied in a case study. However, there are some points that should be discussed about the limitations of the method and about arguments which may be raised.

\subsection{About Uncertainties and Relevant Parameters}

First, some people may raise questions about the definition of the uncertainties and the relevant parameters used for representing these uncertainties. The definitions of the uncertainties are based on the development process of the ventilation system. The detailed parameters are based on the characteristics of typical components, which may be slightly changed if different simulation tools are used. For example, the terrain roughness used in the current research was used for describing the wind reduction factor, while in other simulation tools the wind reduction factor may be directly used.

The valuation of uncertainties is always a difficult task. Sometimes assumptions based on experience are the only method which can be used for valuing some uncertainties. In the current paper, we can only give the possible estimation methods. In certain projects, adequate methods should be chosen based on the trade-off between the requirement of accuracy and cost budget. Better estimation methods may be added besides the methods proposed in the current paper.

The definition and treatment method for uncertainties are mainly based on HRVS with a counter/cross flow heat exchanger and certain commissioning status. If different types of heat recovery units or methods are used or a different commissioning status applies, the method needs to be revised.

\subsection{About Occupant Behaviour}

Concerning the occupant behaviour profile, arguments may be raised whether random occupant behaviour profiles should be used. In the current research, a default occupant behaviour profile was used for two main reasons:

- We focussed on exploring the functions of the ventilation system but not on how the occupant will use the system;

- It is expected that randomly generated occupant behaviour profiles may not provide better results than a default occupant behaviour profile. First, randomly generated occupant behaviour profiles may contain unpractical profiles. No probability functions describing the occurrences of various behaviours are currently available. Furthermore, the behaviour profile in practice could still be quite different from the randomly generated 
ones. Thus, it is not necessarily true that a randomly generated occupant behaviour profile gives better results than a well estimated default occupant behaviour profile.

Actually, the main aim of this research was not to accurately predict the real performance of the system but to find out if the system has enough ability to acquire the wanted performances.

\section{Conclusions}

Different results from research concerning the performance of mechanical ventilation systems with a heat recovery unit may be partly caused by incomparable performance criteria and a lack of considering the influence of various uncertainties.

Adequate criteria should consider the airflow rates, air quality and energy performance and not only focus on a single aspect. The proposed criteria can give a clear overview of the functions of the system.

Various uncertainties may result in large performance deviations of the heat recovery mechanical ventilation system. The uncertainties defined in this paper should be taken into account. Analysing the influence of various uncertainties will provide better understanding of the performance of a ventilation system.

The method proposed in this article can provide an adequate framework for analysing or assessing the performance of HRVS in houses. As such it may contribute to a better understanding and a better design of this type of ventilation system.

\section{References}

Agentschap (2006) NL (SenterNovem), Referentiewoningen nieuwbouw, available from: http://www.rijksoverheid.nl/documenten-enpublicaties/brochures/2010/11/24/referentiewoninge n-nieuwbouw.html.

Costola D, Blocken B, Ohba M and Hensen, JLM: (2010) "Uncertainty in airflow rate calculations due to the use of surface-averaged pressure coefficients". Energy and Buildings, 42 pp881-888.

Dodoo A, Gustavsson L and Sathre R: (2011) "Primary energy implications of ventilation heat recovery in residential building", Energy and Buildings, 43 pp1566-1572. de Wit MS: (2002) "Uncertainty in predictions of thermal comfort in buildings", Doctoral thesis, Delft University of Technology.

Hyun SH, Park CS and Augenbroe GLM: (2008) "Analysis of uncertainty in natural ventilation predictions of high-rise apartment buildings", Building Serv. Eng Res Technol. 29, pp311-326.

Helton JC: (1993) "Uncertainty and sensitivity analysis techniques for use in performance assessment for radioactive waste disposal", Reliability Engineering and System Safety, 42, pp327-367.

Iman RL and Helton JH: (1988) "An investigation of uncertainty and sensitivity analysis techniques for computer models", Risk Analysis, 8, pp71-90.

Iman RL and Helton JH: (1999) "A comparison of uncertainty and sensitivity analysis techniques for computer models", Internal report NUREG ICR3904, SAND 84-1461, Sandia National Laboratories, Albuquerquc, New Mexico, US.

Macdonald IA: (2002) "Quantifying the effects of uncertainty in building simulation", doctoral thesis, University of Strathclyde.

Mckay MD, Beckman RJ and Conover WJ: (1979) "A comparison of three methods for selecting values of input variables in the analysis of output from a computer code", Technometrics, 42, pp55-61.

Morris MD: (1991) "Factorial sampling plans for preliminary computational experiments", Technometrics, 33, pp161-174.

Orme $\mathrm{M}$ and Leksmono N: (2002) "Ventilation modelling data guide", Air Infiltration and Ventilation Centre, GUIDE 05.

Roulet CA, Heidt FD, Foradini F and Pibiri MC: (2001) "Real heat recovery with air handling units", Energy and Buildings, 33, pp495-502.

Schild PG and Brunsell JT: (2003). "Accurate performance testing of residential heat recovery units", In: Proceedings of the 24th AIVC Conference \& BETEC conference - Ventilation, humidity control and energy, pp361-366.

Wouters P, Heijmans N and Loncour X: (2004). "Outline for a general framework for the assessment of innovative ventilation systems", RESHYVENT, WP 4, public report. 